\title{
A Comparative Study of Reading Instruction in Differentially Successful Elementary Schools
}

\author{
Gypsye Dugas Bryan ${ }^{1}$, Evan Ortlieb ${ }^{2, *}$ \& Earl H. Cheek Jr. ${ }^{1}$ \\ ${ }^{1}$ School of Education, Louisiana State University, Baton Rouge, LA, United States \\ ${ }^{2}$ Faculty of Education, Monash University, Frankston, Victoria, Australia \\ *Corresponding author: Tel: 61-3-9904-4661. E-mail: evan.ortlieb@monash.edu
}

Received: June 6, 2013

Accepted: July 4, 2013 Published: July 22, 2013

doi:10.5296/ije.v5i3.3828

URL: http://dx.doi.org/10.5296/ije.v5i3.3828

\begin{abstract}
Elementary schools are positioned to be the epicenter for literacy formation and development, yet many students fail to reach minimum literacy standards. This multiple-case qualitative inquiry focuses on the inner workings of schools that experienced various levels of reading success to determine which programmatic aspects led towards effective reading planning and instruction. Findings revealed that literacy performance is affected by the following causes: the utilization of instructionally appropriate materials to facilitate independent work; scheduling and monitoring of support personnel; management and use of time; assessment practices inform instruction; and continuity within instructional frameworks. This study can assist in setting up professional development, serving as a guide for providing warranted support for student learning and teacher knowledge, and fostering considerations for including teachers in the important stages regarding the planning and implementation of classroom literacy instruction.
\end{abstract}

Keywords: successful schools; literacy; reading; instruction; elementary education 


\section{Introduction}

Only 23\% of Louisiana's public school fourth-graders scored at or above the proficient level on the reading portion of the latest National Assessment of Educational Progress (NAEP, 2011), and $60 \%$ of the state's fourth graders performed below the basic level on that test. Consequently, a large proportion of children in Louisiana schools are not prepared to become productive citizens in society. Teale et al. (2013) describe these as "students placed at risk," a label intended to make the distinction that the fault lies not within the students but within a system that exacerbates their problems. Many of these students live below the poverty threshold; they are confronted with cultural and language differences, race differences, family and community differences; and attend schools that do not consistently impact their learning (Ainsworth, Ortlieb, Cheek, Pate, \& Fetters, 2011; Ortlieb, 2013).

The failure of schools to educate students in basic literacy skills is alarming considering the resources that are available to them (Ortlieb \& Cheek, 2008). For the past 40+ years, schools with enrollments of large numbers of disadvantaged children have been granted supplemental financial assistance under Title I of the Elementary and Secondary Education Act of 1965 (ESEA, 2008) to subsidize educational programming for low-achieving, impoverished children. The Title I federal compensatory education program, initially funded in 1965, was renamed Chapter 1 in the 1980s, and reverted to the name Title I in 1994. Yet some schools continue to fail, even with additional resources designated for these high-poverty schools to remediate students and accelerate learning.

Theodore Sizer (1996) studied schools and school reform for years. In Horace's Hope: What Works for the American High School, he lambasts schools and policymakers for failing to address the needs of students. "Kids are not on conveyer belts, with teachers hanging knowledge on them as they pass by. Schools do not 'deliver instructional services,' pumping up intellectual tires and delivering pedagogical pizza. Children-blessedly-are more complicated and thus more interesting than that” (p. xiii).

\subsection{Significance of the Study}

Over 50 years ago, Rudolph Flesch (1955) emerged as an advocate for the use of phonics in reading instruction in his book, Why Johnny Can't Read and What You Can Do About It, which he wrote specifically for parents. Though professionals in the field of reading did not take him seriously, other stakeholders shared his disenchantment with the state of reading instruction. Time has passed, phonics has resurfaced (Adams, 1990), and the outcry from stakeholders has grown louder. The Public Affairs Research Council (1997) strongly recommended solutions to break the cycle of placing the children of Louisiana at risk, including focusing on the elementary level and targeting its resources to guarantee that every child will learn to read by the end of the third grade. This should not be too much to expect of an education system that taxpayers support to the tune of $\$ 3.5$ billion annually. A child cannot learn history, science, math, and other subjects if he or she cannot read. These sentiments are still echoed today since the National Reading Panel (2001) and the recent adoption of the Common Core State Standards (2010). 
This inquiry is significant from the perspective of looking closely, listening carefully, documenting accurately, and reporting clearly what occurs in schools where children learn to read. Of course, it is just as important to employ the same intensity in studying what went on in schools where children have not learned to read proficiently. Once these similarities and differences are brought to light and pondered deeply, instructional insights can be gained so that learning is optimized. Hence, the problem under investigation is reading instruction in Title I schools with differing school performance levels in literacy. The purpose of the study is to gain an understanding of what occurs in a school where students read proficiently versus schools where struggling to read is commonplace.

\subsubsection{Research Questions}

The following questions guide this research study. Frequent review of these questions promoted constancy of purpose in achieving the goals of this research study:

(a) What resources, time factors, and management systems do elementary teachers use to create an effective reading environment?

(b) How do reading assessment measures and practices inform reading instruction?

(c) What is the level of continuity in reading instruction between classrooms?

\section{Review of Literature}

\subsection{Reading Success in Elementary Schools}

School entry is not the beginning of mental development in its broadest sense, but it is the beginning of society's formal attempts to instruct all children in groups, in skills that are considered important (Christie \& Mission, 2012). Generally accepted as most important of the skills is learning to read, and then reading to learn (Kirby, Cain, \& White, 2012). In a larger sense, language (speaking, listening, reading, or writing) in any form represents an external conventionalized system of communication that exists prior to the child's entry into society. Language contains innumerable devices, forms, and presuppositions that characterize it as a tool of communication (Bruner, 1984; Vygotsky, 2012). Upon entering the formal school setting, a child's challenge is to engage in message-getting and problem-solving activities, which increase in power and flexibility the more they are practiced (Chien et al., 2010). During the first three years of schooling, teachers create environments in which instructional programs are implemented and learning is communicated. "By the child's third year of formal schooling, the eight year old is expected to be: (a) tuned to the meaning of texts, (b) eager to talk and read and write, (c) able to compose and write simple texts; and, (d) able to read narrative and non-narrative texts" (Clay, 1991, p. 10).

Because of the way schools are designed, teachers bear the primary responsibility for students' meeting these educational expectations. Nonetheless, effective teaching is an interaction — albeit one with major aspects occurring outside the teacher's control and within the student. Thus, appropriate classroom settings and relevant assessment systems are vital to 
the adequate facilitation of this interaction. These fundamental components, coupled with clear programmatic goals focusing on individual needs, are considered the most conducive structures to reading success for young children (Ortlieb \& Cheek, 2013).

\subsection{Effective Environments for Learning to Read}

As young children first enter the classroom from the openness of home and community, learning settings change dramatically; hence, so must childhood behavior change. "Space communicates with people-in a very real sense it tells us how to act and how not to act" (Kritchevsky \& Prescott, 1977, p. 9); therefore, creation of physical space becomes a vital part of the learning process. By organizing an environment to support literacy development, resources are provided whereby literacy comes alive and is lived, both by adults and by children (Rennie \& Ortlieb, 2013).

Kritchevsky and Prescott (1977) conducted a landmark research study finding that the most effective predictor of early childhood program quality was physical space, as analyzed by a scheme developed in the course of the three-year study. Successful programs purposefully link physical-space design with clear goals for scheduling individual, group, teacher-directed, and self-selected activities. Functional space, along with curricular content and room organization, promotes curricular goals by allowing goal-related behavior to occur. Also, the space itself neither forces behavior which is contrary to goals nor forces the selection of otherwise unimportant or inappropriate activities as a means of coping with space-induced negative behavior.

The physical environment must be arranged and kept in order, and time must be scheduled for each child to be involved in reading experiences in different areas of the environment. In the lower-elementary classroom, materials, labels, lists, signs, and charts help to organize both activities and the space where they occur. In addition, these learning tools provide functional print experiences for children (Neumann, Hood, Ford, \& Neumann, 2011). Specific literacy events dictate the use of certain instructional materials.

\subsection{Meaningful Assessments in Elementary Reading Instruction}

According to Fountas and Pinnell (2012), assessment has a number of general purposes that form a continuum moving from informal daily classroom assessment to more formal reporting. The purposes for assessment are: (a) continually informing the teacher's decisions for instruction, (b) systematically assessing the student's strengths and knowledge, (c) determining what the student can do independently and with support, (d) documenting progress for parents and students, (e) summarizing achievement over a period of time, and (f) reporting to administrators and other stakeholders in the community.

To ensure that all areas of reading development are assessed, that objective and reliable results are rendered, and those data can be easily shared with parents and other staff members, most educators select one or more valid, researched-based assessment tools. Ortlieb and Cheek (2012) recommend embedding opportunities to assess how students are learning and then use that information to make advantageous changes to instruction. These diagnostic uses of assessment to provide feedback to teachers and students are called formative assessment, 
which lies in contrast to summative assessment, which generally takes place after a period of instruction and requires a judgment about the extent to which learning has occurred.

\subsection{Successful Programming}

Are there designs that schools can utilize to enhance learning of students placed at risk of academic failure? If so, what are their key characteristics, and what steps are required to replicate those programs? Stringfield, Millsap, and Herman (1997) conducted a meta-analysis, finding 10 specialized strategies for simple changes from adding tutors to whole-school reform. They are as follows: (a) James Comer's School Development Program (1988), incorporating collaborative school governance, integrated social services, and parental participation; (b) Success for All (Slavin, Madden, Karweit, Dolan, \& Wasik, 1992), requiring intensive school restructuring and an emphasis on improving reading through small group and tutoring sessions, preschool, full-day kindergarten, and addressing difficulties within the regular classroom; (c) Mortimer Adler's (1983) The Paideia Proposal: An Educational Manifesto, emphasizing challenging material, coaching, higher-order thinking skills, and Socratic seminars; (d) Coalition of Essential (CES) Schools, developed by Theodore Sizer (1984), facilitating restructuring of schools by outlining broad directions for local design and implementation using nine CES principles; (e) school-wide programs virtually eliminating pull-out programs, reducing class size, and increasing staff development; (f) extended year programs, adding school days and more staff development and teacher planning time; (g) Reading Recovery (1985), an intensive first-grade, one-to-one tutoring program developed in New Zealand by Marie Clay in which students spend a half-hour per day with a highly trained reading specialist for up to 16 weeks facilitating students' reading at grade level and having the necessary reading skills to progress further with no remediation; (h) several commercial vendors offering integrated computer-assisted instruction in which students spend a half-hour each day in interactive, computer-driven instruction; (i) tutoring, utilizing commercially-produced and locally-derived material and delivering a highly structured reading, mathematics, and English as a Second Language tutorial program implemented by cross-age peer tutoring or by paraprofessionals; and (j) after-school and summer programs making available more and varied instructional activities designed for students who are not able to keep up at the rate of their peers.

These programs had common characteristics: (a) students placed at risk are capable of achieving at levels that meet the national average; (b) there is great variance in both implementation levels and effects; (c) schools obtaining the greatest academic gains paid close attention to issues of initial and long-term implementation; (d) promising programs that concentrated on early grades obtained larger achievement gains from students placed at risk than did programs spreading resources more evenly over the elementary grades or in secondary schools; (e) instruction is driven by management issues, uneven access to subjects beyond reading/language arts and math, and reforms stifled by simplistic issues such as scheduling; (f) resources are in short supply; (g) Chapter 1 is the primary engine for reform in otherwise distressed schools; and (h) most programs are continuing to evolve and improve. 


\section{Methods}

\subsection{Design}

The multiple-case report, for which the entire report consists of the cross-case analysis in which each section would be devoted to a separate cross-case issue (Yin, 2003), facilitated the purpose of this research endeavor, which was to gain understanding of what occurred in schools with similar students who achieved at different levels. Designed to describe and analyze reading instruction in four Title I elementary schools, this study focused on two successful schools with high achievement scores and two unsuccessful schools with low achievement scores. Each of the four schools served as a single case with a concluding analysis to communicate the cross-school similarities and differences impacting reading instruction in the schools.

Yin (2003) suggests setting geographic and time boundaries to define beginning and end of the case. To that end, four elementary schools, within a large school district of 99 schools, were chosen, thus defining the geographic boundaries. The time of the study was bound within the one academic school year and the subsequent summer, when long-term immersion facilitated the gathering of comprehensive, systematic, and in-depth data about reading instruction in the four participating schools; member checking with teachers at school sites; intermittent peer debriefing; and external auditing.

Six types of case study evidence shaped the data set: documentation, archival records, interviews, direct observations, participant observations, and physical artifacts. Each played an important part in the gathering of information. For this reason the following principles of case study research were employed during the course of this inquiry: (a) the use of multiple sources of evidence; (b) creation of a case study database; and (c) maintenance of a chain of evidence by engaging an external party to follow the derivation of evidence from initial research questions to ultimate case study conclusions.

\subsection{Participants}

The Relative Performance Indicator (RPI) scores were a major factor in selecting schools for participation in this research study. In addition to the schools' ranking by RPI score, calculated through regression analysis, other factors were considered when making final school selections for participation. District-level input regarding the following issues were weighed: equitable racial composition of school principals, school inclusion in other studies, past administrative effectiveness, and the principal's willingness to participate in the study.

Researchers contracted by the Read Independent School District calculated the RPI from public records data supplied by the Louisiana State Department of Education. The RPI was not a part of the data reporting system of the State Department of Education; however, Read Independent School District had this information calculated to gain a clearer picture of district school performance.

The RPI for each school was calculated through a regression analysis in which five variables were used to predict a combined score from criterion-referenced-tests (CRT) and 
norm-referenced-tests (NRT). The variables used in the statistical procedure were: (a) socioeconomic factors, (b) community type, (c) percent special education students, (d) percent language-minority students, and (e) percent gifted students. As a result, each school had an RPI score in addition to their CRT and NRT scores. Positive RPIs indicate that the school exceeded prediction, while negative RPIs indicate that the school fell below prediction. The average RPI was 0.00 , with a standard deviation of 1.00. Of the 99 schools in the Read Independent School District, there are 39 Title I elementary schools. RPIs for elementary schools in the district ranged from +1.2797 to -2.1702 . Scores below -1.0 were given a rating of low, those from -.999 to -.501 were given a rating of low/medium, and those from -.50 to +.50 were given a rating of medium. Medium/high ratings were designated for +.501 to +.999 , and high ratings were given for scores from +1.0 and above.

Given the purpose of this study - to describe reading instruction in differentially successful schools - schools fitting the extreme or deviant purposeful sampling criteria were selected. As suggested by Patton (1990), the purpose of this sampling strategy was "learning from highly unusual manifestations of the phenomenon of interest, such as outstanding success/notable failures. ..” (p.182). After additional consultation with district administrators, the two unsuccessful schools were selected from the low category with the successful schools coming from the high and medium/high categories.

\subsection{Ethics}

"Because qualitative methods are highly personal and interpersonal, because naturalistic inquiry takes the researcher into the real world where people live and work, and because in-depth interviewing opens up what is inside people-qualitative inquiry may be more intrusive and involve greater reactivity than surveys, tests, and other quantitative approaches" (Patton, 1990, p. 356). As such, every effort was made to address issues in a professional and ethical manner while implementing this qualitative study. Ethical issues of concern were informed consent, beneficence, individual rights to privacy, dignity, and avoidance of harm (The Belmont Report, 1978). The identities of all individuals participating in the study were kept confidential and reported as pseudonyms. Identities of the participating schools remained anonymous as well.

\subsection{Data Collection and Analysis}

Qualitative methods consist of three kinds of data collection: a) in-depth, open-ended interviews, b) direct observation, and c) written documents (Patton, 1990). Utilizing all of these data collection techniques in this inquiry corroborated the findings and served as triangulation of data sources. Therefore, evidence for this research study was collected through prolonged engagement with selected professional staff at each school site using the following: (a) interviews were conducted one-on-one with principals and classroom teachers of reading; (b) focus groups were facilitated for eight to ten randomly selected teachers at each site; (c) observations were made in each reading class; and (d) written documentation was perused and analyzed.

Data were analyzed for each strategy following the respective protocol. Data were analyzed 
inductively, starting with raw units that were eventually sorted and classified into more comprehensive categories (Lincoln \& Guba, 1985). Therefore, for all protocols employed, data analysis was an ongoing activity from entry into the field through member checks and into the final external audit.

Information gathered for each school was analyzed, synthesized, and reported as an individual case. Each report presented a narrative overview of the school context with a general description of the findings as they evolved during the course of the inquiry. The Developmental Research Sequence (Spradley, 1979) was employed to analyze the evidence gathered during classroom observations and individual interviews. The procedures for this protocol are sequenced from simple to complex in a hierarchy within which data collection and analysis build on and from each other.

Students' time on task (TOT), using the Revised Classroom Snapshot, was reported as a school-wide percentage of students' time being spent engaged in learning during reading class. This percentage was derived by averaging individual class TOT scores. The Louisiana Components of Effective Teaching (LCET), which was administered as a part of the observation protocol, was reported as a school-wide score ranging from 1-4. The four-point rating scale was used as follows: 4-demonstrates excellence; 3-area of strength; 2-needs improvement; and 1-unsatisfactory. The 19 attributes are divided into management and instruction domains which relate to the first research question of this study.

\section{Findings}

Elementary school teachers are adults who accept responsibility for teaching groups of children to read. In the course of this study, the numbers of students forming groups with one teacher varied from 16 in some situations to 28 in other situations. There were many instances of isolated interaction between one teacher and one student; but during that one-on-one teaching time, the teacher was responsible for having prepared instructional-level activities for the other 20+ students in the class. All certified teachers in this study could teach one student to read, one at the time. Reading instruction became a challenge when the one six-year-old student became 1 of 27 six-year olds in the same confined area for eight hours a day, 180 days a year. Therefore, findings from this inquiry revolve around, emanate from, and fold back into each teacher's ability to lead her students to read by effectively managing their instruction. One teacher, however, is just a part of the bigger picture. Since the unit of analysis for this study is the school, the school administration, namely the principal, was an integral part of the findings.

It is important to note that in the delivery of reading instruction in this study, no one method, approach, technique, grouping arrangement, instructional material, basal text, or mode of operation was found to prevail solely at any of the sites. Thus, this research did not uncover one method that could be suggested as superior to another. Just as Stringfield, Millsap, and Herman (1997) found, when they evaluated 10 Title I programs across 25 sites over a three-year period, that: (a) all programs across sites had strengths, yet there was great variance 
in implementation; (b) schools obtaining the greatest academic gains paid close attention to issues of initial and long-term implementation; (c) instruction was driven by management issues such as scheduling and uneven access to subjects beyond reading/language arts and mathematics; and (d) not surprisingly, resources were in limited supply.

This inquiry addressed three questions about reading instruction in Title I elementary schools. Analysis of field notes structured emerging themes of a story with setting, character, and plot coalescing to form thick descriptions only to be analyzed and restructured like problems in the resolution phase of a story. The following summary of findings relates this study to the solving of a problem in the resolution element of a story cycle.

\section{$\underline{\text { Question A }}$}

What resources, time factors, and management systems do elementary teachers use to create an effective reading environment?

In responding to what teachers use to create environments conducive to reading instruction, it is worthwhile first to look at what teachers say they need in order to adequately create these environments. When asked across sites, the highest priority needs reported by teachers were lower pupil-teacher ratio and more books along with increased consumable materials. Human resources as well as materials were resources that teachers reported they value and lack.

Regarding human resources, across sites, scheduling ancillary teachers was the most often employed strategy used to reduce pupil to teacher ratio in reading classes. Yet, effective scheduling and organizing of ancillary teachers' time to benefit student need while meeting school goals was one resource found to be lacking in three of four schools studied. In all schools only the principal with benefit of the whole picture had the power to hire personnel, schedule classes, monitor those classes, and give timely feedback. This cyclical function was apparent only at Brookfield School.

It was interesting to note that of the schools in the study, when asked to list their needs, Brookfield had the fewest number of teachers citing lowering pupil-teacher ratio need. Not to dismiss teachers' stated needs, but it is suggested that only when personnel already on staff in schools are appropriately utilized should this teacher-stated concern be addressed. Having Friday away from the students, not planning with classroom teachers, not having regularly scheduled classes, and leaving the students unattended with no certified teacher in the room ... these are but a few of the types of situations observed during the course of this study. Therefore, lowering the ratio of students to teachers is a management issue, a time issue, and an accountability issue.

With regard to the materials needed, many of the teachers spoke of buying materials with their own funds, writing grants, and enlisting family members to assist with classroom projects. At three of the four schools, the principals were overtly supportive of teachers' getting what they needed for their classes. Teachers are very creative. At Brookfield they used the old basal texts for skills and the new basal for listening and literature; the TIS at Bayside Elementary went to the book depository to get old materials; the TIS at Brookfield Elementary brought units and the accompanying paraphernalia to "her" teachers. The finding in this study regarding 
resources was positive with respect to materials and generally bleak with respect to human resources. Staff development as a human resource was relatively similar across sites with teachers complaining about the timing and lack of training in the area of writing.

Use of time was a revealing find. From site to site it was interesting to see how time was managed. Having teachers do morning planning in their classrooms was an excellent way to start the day with students being afforded the opportunity to do review work. As a result, at Star Two, 30 minutes were added to instruction time and 25 minutes were added at Brookfield. Having one recess per day cut down on the lost "pass time." At Brookfield the lower grade levels had recess after lunch separate from the rest of the school. Blocking for reading cut down on the ancillary and pull-out interruptions.

An additional time factor was the policy of planning school assemblies by grade level so that they were relevant to student developmental and educational needs. Also, the principal making time to visit each classroom at least once a day reinforced for students why they were at school, especially when she would check their work and make comments about their report cards. Time for planning with colleagues was another component used to create an effective reading environment. Teachers at Brookfield came to school 15 minutes early at least once a week to meet with grade level teachers for 30 minutes before going to individual classrooms to greet students. Occasionally they would meet during the school day. At other sites in the study, teachers met weekly for an hour during the school day and monthly for a half-day.

Departmentalization in the upper grades was a part of the management system at the two successful schools in this study. Centers as a resurrected mandate in the district drew attention to teachers' lack of skill in the area of classroom management. Only at Brookfield were the students engaged during center time with adequate and appropriate activities. This was a rigid process that suggested a very controlled beginning of a management scheme new to the students. Students at this school rarely were idle. Yet teachers at Brookfield, by omitting the element of choice in centers, were not afforded the opportunity to use students' choices as an assessment strategy.

The findings in this study are consistent with those of Brophy (1988) who concluded that academic learning time is influenced by the amount of time students spend engaged in appropriate academic activities; and, students' learning is strengthened "when teachers instruct them actively by structuring new information and helping them relate it to what they already know, and then monitoring their performance and providing corrective feedback” (p. 275).

\section{$\underline{\text { Question B }}$}

How do reading assessment measures and practices inform instruction?

Historically, most assessment has been directed to the outcomes of instruction (Wilson \& Calfee, 2012). We wait until the end of the instruction sequence before we assess: monitoring for national performance, assessing effectiveness of schools and teachers, and assessing elementary school outcome achievements. "When we measure the outcomes of teaching with important tests the instruction of learners is already over" (Clay, 1993). If we try to use those results to improve instruction, we can only guess what factors produced the scores and guess 
further how to change our policies for corrective actions. Effective teaching calls for assessment designed to record how the student works on tasks and to inform teaching as it occurs (Ortlieb \& Cheek, 2012). In response to questions about assessment practices, teachers across sites were defensive and vague. As the study progressed and data were analyzed, it became apparent that assessment was a weak link in the instructional chain within each school, albeit at varying degrees. For example, Tanton Elementary had a school-wide writing component in the language arts program undergirded by the writing rubric, and Brookfield had a more comprehensive school assessment design which was more school level than classroom engendered. At Brookfield School, from the time a student registered throughout his or her academic experience there was ongoing formal assessment. As soon as problems began to appear, teachers would go to the guidance counselor who did language processing, I.Q., and dyslexia screening. Once a problem was detected it would be addressed. Any child who did not qualify for special services was provided with special accommodations and modifications in his or her instructional program. Volunteers who tutor students at the school work under the direction of the guidance counselor. Their work was monitored, and they were given feedback. But these are not informal assessment practices that guide classroom instruction (Cheek, Flippo, \& Lindsay, 1997).

Teachers used varying informal and intuitive assessment measures as a part of reading class. For some, making a running record of students' reading miscues helped to set up the next steps in reading instruction; for others informal reading inventories were given to ascertain instructional reading levels; yet, in many classes all students were instructed using the same grade level basal. Many teachers tested on Fridays, did pre/post-testing in skill grouping, and gave basal unit tests. Most of the teachers spent ample instructional time on standardized test preparation - a strategy that placed higher value on measuring outcomes than utilizing assessments to guide teaching (Clay, 1993).

Another disappointing find across the sites was the lack of consistency from grade to grade within each school regarding policies for documenting student progress, organizing work samples, setting uniform standards for showcase portfolios, and making decisions about what pertinent documents should be included in a literacy folder for charting and communicating student progress. There was, however, a positive indication that the district was beginning to approach informal student assessment as a viable and necessary partner to formal assessment. This assumption is made with the inclusion of portfolio assessment as a component of the district-wide K-3 Initiative.

\section{$\underline{\text { Question C }}$}

Within the context of the school, what is the level of continuity in reading instruction from one classroom to the next?

Having continuity from classroom to classroom was evident at one school which contributed to that school's sense of unity. Regardless of each teacher's theoretical orientation in reading instruction, demonstrating similar pedagogy at grade level appeared an important key to children learning to read at Brookfield School. Within the walls of each school studied, there were teachers with differing theoretical orientations in reading instruction. Yet, in the 
successful schools, teachers planned and implemented similarly. At Brookfield, teachers planned together for the purpose of implementing like-programs and used time wisely so as not to take away from instruction time with students. The quality of instruction at most grade levels was high, and classroom management skills were rated high, demonstrating consistency within the grade levels. Data from Brookfield School fit the image of a successful school as defined in a 1994 research report. Findings from a study of 21 highly regarded Title I Schools conducted by Pechman and Fiester (1994) revealed that successful schools build on a framework that includes the following eight features. The first six of these features were evident at Brookfield School; the remaining two may have been present, but did not emerge in the course of the study: (a) shared vision, (b) time and resources for planning and program implementation, (c) skillful management and a well-defined organizational structure, (d) clear focus on academics, (e) continuing professional development, (f) commitment to cultural inclusion, (g) parent and community involvement, and (h) accountability orientation.

Factors supporting continuity from classroom to classroom at Brookfield School were low absenteeism, high stability, and advanced degrees among faculty, along with a highly visible, established principal. These factors were foundational to the relative lack of discipline problems at the school which led to teachers' high expectations implicit in their positive comments about students who attend "their" school.

Woven through the Meadows School reading program was active participation of the school librarian. Her immersion in the instructional program is an indication that fundamental beliefs and counter-designed district mandates can co-exist. Over a seven-year period she has been involved in reading programs from single basal to literature-based to K-3 Initiative, and she continued to have a prevailing presence in school-wide reading instruction.

At the two successful schools, the principals were reluctant to make rapid, wholesale programmatic changes. This finding suggests that caution with district mandates helped to build confidence with teachers. Veteran teachers were quick to point out, "We have seen programs come and go.”

\section{Conclusion}

This multiple-case qualitative inquiry focused on the inner workings of schools where students placed at risk learned to read, and examined schools where similar students did not learn to read. Research conducted in four elementary schools addressed the following questions: (a) What resources, time factors, and management systems do elementary teachers use to create an effective reading environment?; (b) How do reading assessment measures and practices inform instruction?; and (c) What is the level of continuity in reading instruction between classrooms?

The case studies include factors in schools that affect student learning. Four general findings emerged in response to the research questions. First, material resources were in short supply; and teachers did not utilize instructional-level appropriate materials to facilitate independent work. Human resources were squandered. In the majority of cases, ancillary teacher behaviors 
were counterproductive to student learning. These support personnel were scheduled inefficiently and were inadequately monitored. In a more positive light, frequent principal classroom visitations impacted student and teacher performance. Second, management and use of time were not maximized in the two unsuccessful schools. In the two successful schools, learning time was extended by 30 minutes each day as a result of efficient time management; upper grades were departmentalized; and at one school, pull-out rather than inclusion was implemented for specialized instruction. Third, assessment practices limited rather than informed instruction. Teachers used intuition for informal assessment and inconsistent documentation for reporting. Finally, continuity was apparent at only one site, Brookfield School, where grade-level teachers implemented like-reading instruction within each of the six grade levels. As the data were analyzed and reported, it appeared that there was only one truly successful school in this study-Brookfield School.

Several aspects of the Brookfield instructional program worthy of consideration for transferability to other school sites include: principal as the main teacher; continuous assessment driven by the guidance counselor; no foreign language instruction; departmentalized upper level instruction; classrooms monitored by the principal for team teaching or, if not possible, use of pull-out instruction to meet special student needs; coordination of school programs and field trips with curriculum standards; academic-focused non-class time with the teacher; and explicit articulation of expectations with communication mechanism for feedback.

\subsection{Implications for Further Study}

This qualitative study serves as a catalyst for further study by providing findings that are specific to four school sites. Defining cause and effect relationships was not the intent of this inquiry. Thick descriptions (Yin, 2011) were presented for the construction of meaning about the setting, character, and plot at these sites, not for generalizability of the findings. The transferability of outcomes from this inquiry must be determined by other professionals who wish to apply these outcomes to other situations.

The areas of focus for this inquiry were quite broad, lending support to a need for further in-depth study of issues impacting students' learning to read. From this inductive investigation, several quantitative research projects could be designed with the intention of meeting positivistic validity and reliability standards of generalizability. Several topics for further study might include: time on task of ancillary personnel in elementary reading instruction, comparison between departmentalized and self-contained reading instruction in upper elementary grades, center utilization correlated to increased student reading ability, teachers' theoretical orientation in reading instruction and mandated methodology correlated to student achievement, the relationship of principal time spent with students to achievement, and, finally, an in-depth qualitative look at literacy learning through the communicative and visual arts focusing on the use of technology.

As a result of an obvious void across sites, the area most in need of comprehensive study is assessment. Although there was limited use of fundamental informal assessment practices, there was no evidence of teachers using the computer as a tool for electronic assessment. 


\section{References}

Ainsworth, M., Ortlieb, E., Cheek, E., Pate, R., \& Fetters, C. (2011). First grade teachers' perception and implementation of a semi-scripted reading curriculum. Language and Education, 25(7), 1-14. http://dx.doi.org/10.1080/09500782.2011.618540

Au, K. H., Carroll, J. H., \& Scheu, J. A. (1997). Balanced literacy instruction: A teacher's resource book. Norwood, MA: Christopher-Gordon.

Berk, L. E., \& Winsler, A. (1995). NAEYC Research into Practice Series, Vol. 7. Scaffolding children's learning: Vygotsky and early childhood education. Washington, DC: National Association for the Education of Young Children.

Brophy, J. (1988). Research linking teacher behavior to student achievement: Potential implications for instruction of Chapter 1 students. Educational Psychology, 23(3), 235-286.

Bruner, J. (1984). Language, mind, and reading. In H. Goelman, A.A. Oberg, \& F. Smith (Eds.), Awakening to literacy (pp. 193-200). Exeter, NH: Heinemann.

Chall, J. S. (1983). Stages of reading development. New York: McGraw-Hill.

Cheek, E. H., Flippo, R. F., \& Lindsey, J. D. (1997). Reading for success in elementary schools. Madison, WI: Brown \& Benchmark.

Chien, N. C., Howes, C., Burchinal, M., Pianta, R. C., Ritchie, S., Bryant, D. M., \& Clifford, R. M., et al. (2010). Children's classroom engagement and school readiness gains in prekindergarten. Child Development, 81(5), 1534-1549.

Christie, F., \& Misson, R. (2012). Framing the issues in literacy education. In F. Christie \& R. Mission (Eds.), Literacy and schooling (pp. 1-17). New York: Routledge.

Clay, M. M. (1991). Becoming literate: The construction of inner control. Portsmouth, NH: Heinemann.

Clay, M. M. (1993). An observation survey of early literacy achievement. Portsmouth, NH: Heinemann.

Flesch, R. (1955). Why Johnny can't read and what you can do about it. New York: Harper \& Row.

Fountas, I. C., \& Pinnell, G. S. (2012). Guided reading: The romance and the reality. The Reading Teacher, 66(4), 268-284.

Geertz, C. (1973). Thick description: Toward an interpretive theory of culture. In C. Geertz (Ed.), The interpretation of culture (pp. 119-161). New York: Basic Books.

Kirby, J. R., Cain, K., \& White, B. (2012). Deeper learning in reading comprehension. In J. R. Kirby \& M. J. Lawson (Eds.), Enhancing the quality of learning: Dispositions, instruction, and learning processes (pp. 315-338). New York: Cambridge. 
Kritchevsky, S., \& Prescott, E. (1977). Planning environments for young children physical space. Washington, DC: National Association for the Education of Young Children.

Lincoln, Y. S., \& Guba, E. G. (1985). Naturalistic inquiry. Thousand Oaks, CA: Sage.

Naitonal Governors Association Center for Best Practices, Council of Chief State School Officers. (2010). Common core state standards. Washington, D.C.: Author.

National Center for Education Statistics, Institute of Education Services. (2011). The nation's report card: Reading 2011: National Assessment of Educational progress at Grades 4 and $8 . \quad$ Washington, D.C.: Author. Retrieved from http://nces.ed.gov/nationsreportcard/pdf/main2011/2012457.pdf

Neumann, M. M., Hood, M., Ford, R. M., \& Neumann, D. L. (2011). The role of environmental print in emergent literacy. Journal of Early Childhood Literacy, 12(3), 231-258.

Ortlieb, E. (2013). Struggling to read: Not just an urban problem. Journal of Sociological Research, 4(1), 195-206. http://dx.doi.org/10.5296/jsr.v4i1.2046

Ortlieb, E., \& Cheek, E. H. (2008). How geographic location plays a role within instruction: Venturing into both rural and urban elementary schools. Educational Research Quarterly, 32(1), 48-64.

Ortlieb, E., \& Cheek, E. H. (Eds.) (2012). Literacy Research, Practice, and Evaluation: Vol. 1. Using informative assessments for effective literacy instruction. Bingley, UK: Emerald Group.

Ortlieb, E., \& Cheek, E. H. (Eds.) (2013). Literacy Research, Practice, and Evaluation: Vol. 3. School-based interventions for struggling readers, K-8. Bingley, UK: Emerald Group.

Patton, M. Q. (1990). Qualitative evaluation and research methods ( $2^{\text {nd }}$ ed.). Newbury Park, CA: Sage.

Pechman, E. M., \& Fiester, L. (1994). Implementing schoolwide projects: An idea book for educators. Washington, DC: U.S. Department of Education.

Rennie, J., \& Ortlieb, E. (2013). Diverse literacy learners: Deficit versus productive pedagogies. In E. Ortlieb \& E. H. Cheek, Jr. (Eds.), Literacy Research, Practice, and Evaluation: Vol. 3. School-based interventions for struggling readers, K-8 (pp. 203-218). Bingley, UK: Emerald Group.

Sizer, T. R. (1984). Horace's compromise: The dilemma of the American high school. Boston: Houghton Mifflin.

Sizer, T. R. (1996). Horace's hope: What works for the American high school. Boston: Houghton Mifflin.

Slavin, R. E., Madden, N. A., Karweit, N. L., Dolan, L. J., \& Wasik, B. A. (1992). Success for all: A relentless approach to prevention and early intervention in elementary schools. 
Arlington, VA: Educational Research Service.

Spradley, J. P. (1979). The ethnographic interview. New York: Holt, Rinehart and Winston.

Teale, W. H., Lyons, K., Gambrell, L., Zolt, N., Olien, R., \& Leu, D. J. (2013). An online learning community as support for at-risk students' literacy growth: Findings, implications, and challenges. In A. Shamir \& O. Korat (Eds.), Technology for literacy achievement in children at risk (pp. 141-156). Dordecht, Netherlands: Springer.

Vygotsky, L. S. (2012). Thought and language. Cambridge, MA: MIT Press.

Wilson, K., \& Calfee, R. (2012). Inquiry-based formative assessment for improving student learning. In E. Ortlieb \& E. H. Cheek, Jr. (Eds.), Literacy Research, Practice, and Evaluation: Vol. 3. School-based interventions for struggling readers, K-8. Bingley, UK: Emerald Group.

Yin, R. K. (2003). Case study research: Design and methods ( $2^{\text {nd }}$ ed.). Thousand Oaks, CA: Sage.

Yin, R. K. (2011). Qualitative research from start to finish. New York: Guilford Press.

\section{Copyright Disclaimer}

Copyright reserved by the author(s).

This article is an open-access article distributed under the terms and conditions of the Creative Commons Attribution license (http://creativecommons.org/licenses/by/3.0/). 